\title{
أثر استخدام وسيلة فيديو التعليم الخاصّ في نتيجة التلاميذ الدّراسية في تعليم الخطّ العربي
}

\author{
Miftahul Janah \\ MA Ibnu Rusyd Bandung \\ Coresponding Email: miftahuljanah208@yahoo.co.id
}

\section{ملخص البحث}

كانت التلاميذ في الدّرس الإضيافي للخطّ العربي بمدرسـة ياسفيكا الثانوية الإسلامية كونينجان يصعبون فيه. ولذلك، يحتاج المدرس إلى العمل التي تؤثر في نتيجة التلاميذ في تعليم الخطّ العربي باستخدام وسيلة لإسيلة

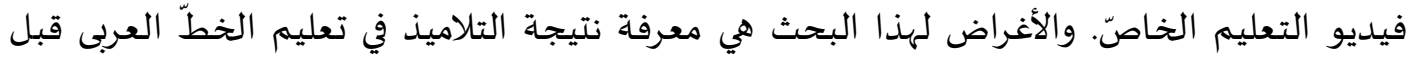

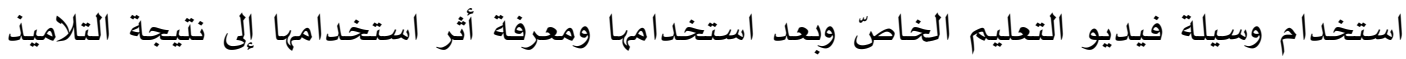
الدّراسية للخطّ العربي. والطريقة المستخدمة هي الطريقة التجريبية بتصيميم الاختبار القبلى والإختبار

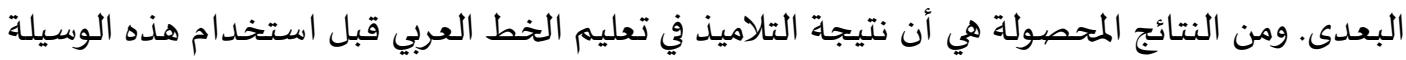

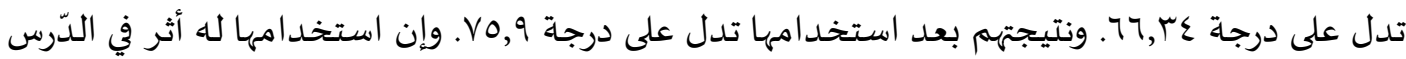

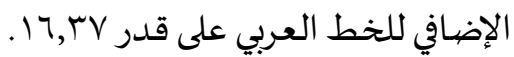

الكلمات الرئيسية:وسيلة فيديو التعليم الخاصّ، نتيجة التلاميذ، تعليم الخطّ العربي.

\begin{abstract}
Abstrak
Berdasarkan fenomena yang terjadi, para siswa yang mengikuti program ekstrakulikuler kaligrafi di MTs Yaspika Kuningan mengalami banyak kesulitan pada bidang kaligrafi. Oleh karena itu, guru membutuhkan banyak upaya yang mampu mempengaruhi pada hasil belajar siswa dalam pembelajaran kaligrafi, salah satunya menggunakan media video tutorial. Tujuan penelitian ini adalah untuk mengetahui hasil belajar siswa pada pembelajaran kaligrafi sebelum dan sesudah menggunakan media video tutorial, serta mengetahui pengaruhnya terhadap hasil belajar siswa. Metode yang digunakan pada penelitian ini adalah metode eksperimen model pree test dan post test design. Hasil dari penelitian adalah bahwa hasil belajar siswa pada pembelajaran kaligrafi sebelum menggunakan media video tutorial menunjukkan pada kategori nilai 66,34. Hasil belajar mereka setelah menggunakan media video tutorial menunjukkan pada kategori nilai 75,9. Serta penggunaan media video tutorial memiliki pengaruh terhadap hasil belajar siswa pada program ekstrakulikuler kaligrafi karena nilai t hitung 16,37 .
\end{abstract}

Kata Kunci: Hasil Belajar, Media Video Tutorial, Pembelajaran Khat Arab. 


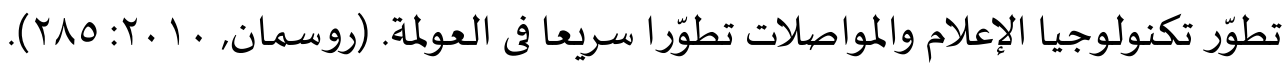

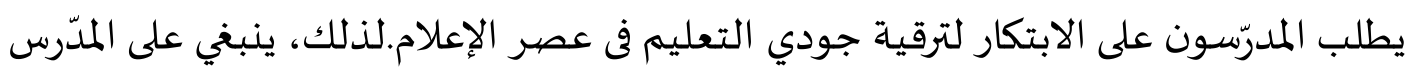

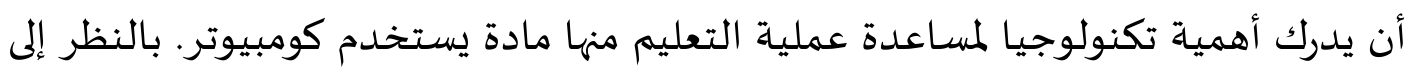
هذا، المواد الدراسية باستخدام الكومبيوتر، لازم على المدرّس أن يقوم بالتعلم على لتجديديد.

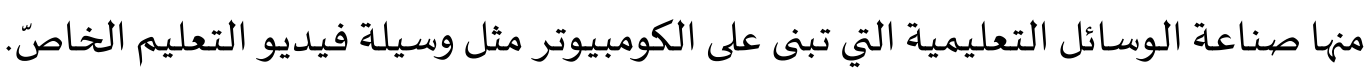

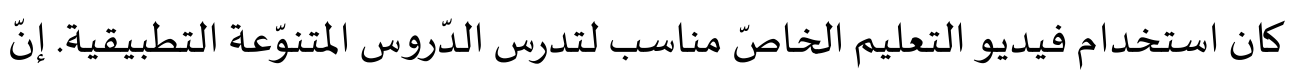

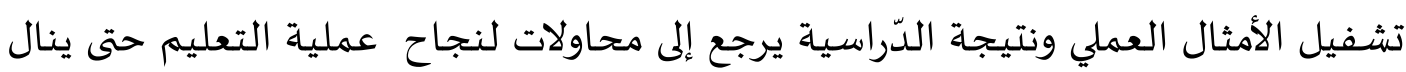

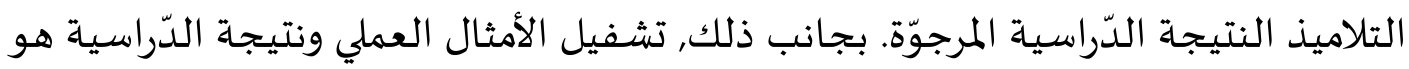
المحاولة الجيّدة لعملية التعليم حتى يتواصل إلى التلاميذ نجاح العمل والنتيجة الدّراسية.

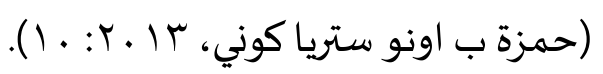

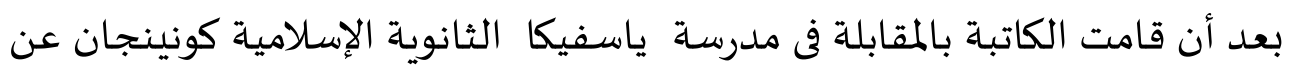
درس الخط وجدت أن هناك مشكلات عديدة في تعلّم الخط منها أنّ كثير من التلاميذ لم

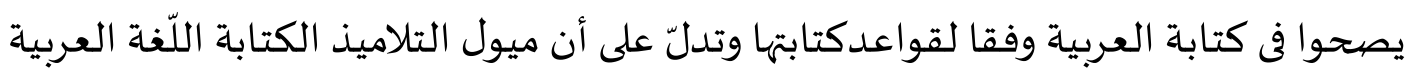
منخفض وخلفيتهم مختلفة الدرسية. وهذه الحالة يسبّب على نتيجة التلاميذ في الكتابة

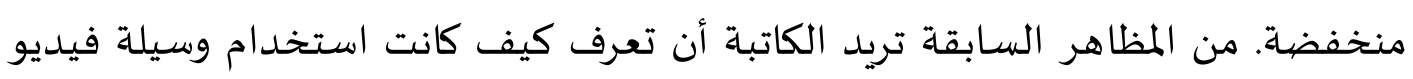

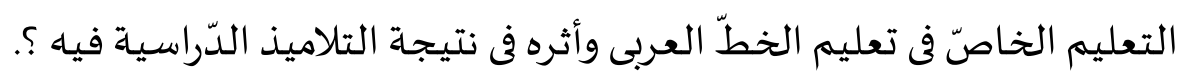

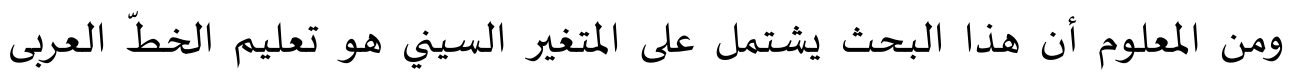
باستخدام وسيلة فيديو التعليم الخاصّ. والمتغير الصادي هو نتيجة التلاميذ الدّراسية فياه. فالفرضية المقترحة التي عارضها الباحثون هي: أن هناك أثر بين استخدام وسيلة

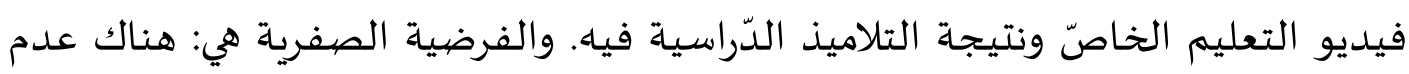
الأثر بين استخدام وسيلة فيديو التعليم الخاصّ ونتيجة التلاميذ الدّراسية فيها. هذا البحث بحث كمي علي الطريقة التجريبية. بتصهيم الاختبار القبلى والاختبار

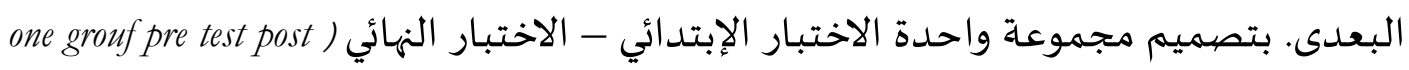

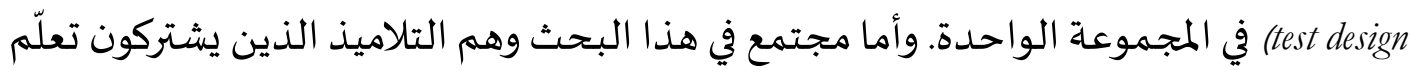
الخطّ العربى في الدّرس الإضافي للخطّ العربي بمدرسة ياسفيكا فئها الثانوية الإسلامية كونينجان

وعددهم 0ب تلميذا. 
مفهوم وسيلة فيديو التعليم الخاصّ

عرف نائف محمود معروف فقد عرف الوسائل التعليمية هي ما يلجأ إلياه المدرّس من

أدواتٍ وأجهزة ومواد لتسهيل عملية التعلّم والتعليم وتحسينها وتعزيزها. وهي تعليمية لأنّ مهن

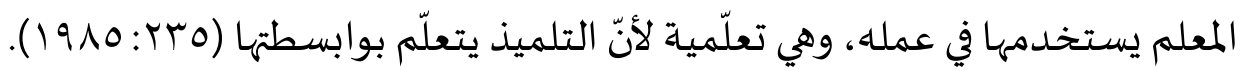

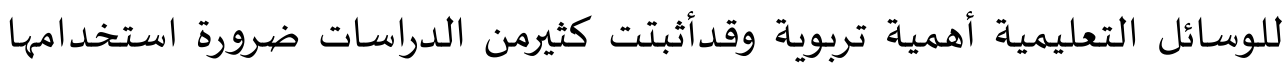
ودورها في رفع مستوى تحصيل الطلبة، وخاصاة بعد أن اتسعت المناهج الدراسية وتعددت جوانبها وأصبحت المعارف والمعلومات تزداد يوما بعد يوم وتأتي من جهات ووسائط عدة، نظرا لتطور وسائل الاتصال وتعدد وسائل المعرفة ومصادرها. ويمكن تلخيص الدور الذي تلعباه الوسائل التعليمية في عملية التعليم والتعلم هي إثراء التعليم، تحقيق اقتصادية التعليم، ولمديه المساعدة على استثارة اهتمام التلميذ وإشباع حاجته للتعلم، المساعدة على زيادة خبرة التلميذ مما يجعله أكثر استعدادا للتعلم، المساعدة على اشتراك جميع حواس المتعلم في

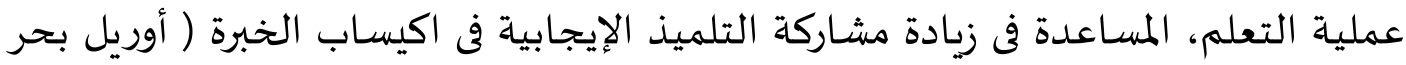

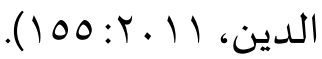

لقد تطورت الوسائل التعليمية كما تطور الأزمان، فمنها ما تعتمد على اللغة اللفظية أو المسموعاة، ومنها ما تعتمد على الصور والرسوم والتسجيلات الصوتية، ومنها ما تعتمد على

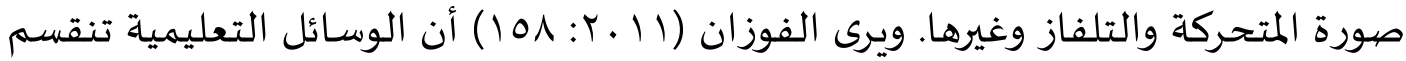
إلى مجموعات، وذلك حسب الحاسة التي تخاطبها، وهي الوسائل التعليمية بشكل المواد

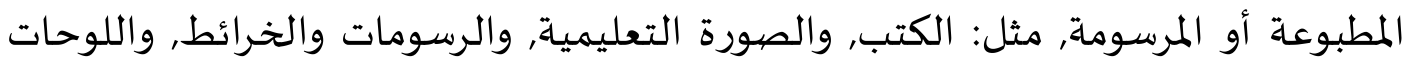
التعليمية, والشفافيات, و البطاقات, والرموز. الوسائل التعليمية بشكل المواد السمعية

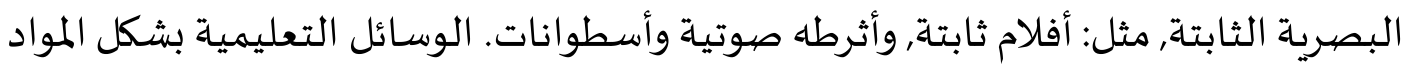
السمعية البصرية المتحركة, مثل: أفلام متحركة،, وأشرطة الفيديو، وأقراص الحاسوبه وقال روسمان إن التعليم الخاصَ هو تعليم يستخدمة المدرَس في عملية تعليمية باستخدام الأدوات اللينة الكومبيوتر وفية مادَة وأسئلة. فضغطه يقع فى السعي لكثرة نشاط

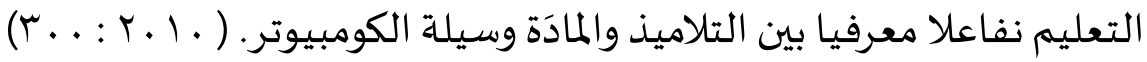


أَمَا خطوات استخدامها هي: (أ) عرض كومبيوتر المادَة، (ب) يعطي التلاميذ الإجابية،

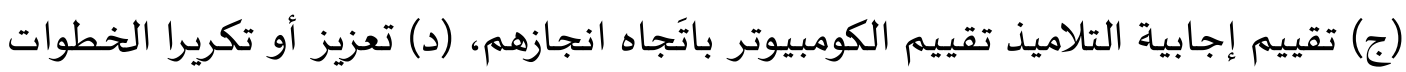

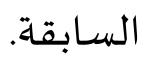

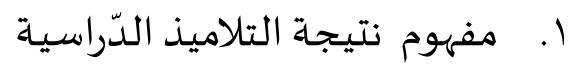

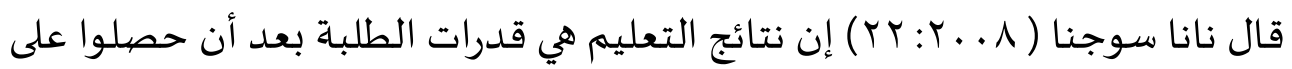
تجرباة تعلمهم.

إن إنجاز الدراسية يؤثر في العوامل العديدة التي تنقسم إلى قسمين : العوامل

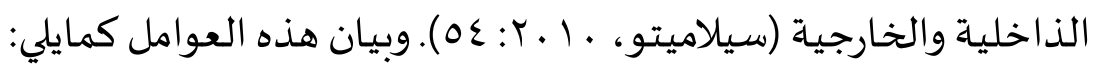

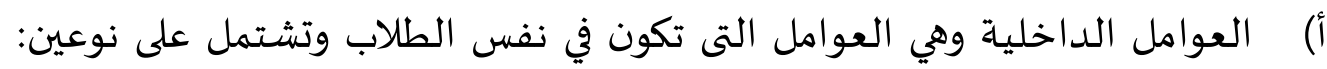
العوامل الجسمية والعوامل النفسية. ب) العوامل الخارجية هي العوامل التي جارج الطلاب. هناك ثلاثة أنواع تؤثر في إنجاز

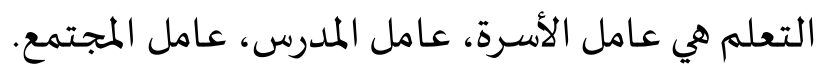
المؤشرات في النتيجة مشتملة على ثلاثة مجالات هي المجال المعرفي والمجال الوجداني المعاني

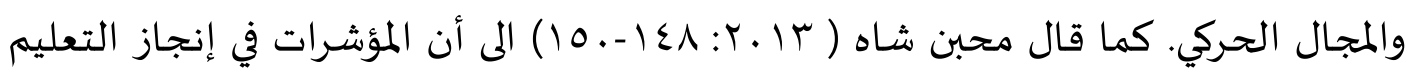

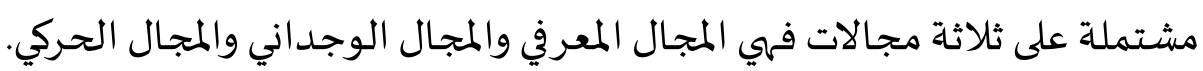

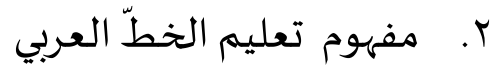
وقال شيخ شمس الدين أنّ الخط هو علم يعرف باء نوع الحروف ووضعها وطريقة نظمها حتى تكون كتابة وطريقة كتابتها وتعيين كل مايحتاج إلها وتغيير الهجاء وطريقة

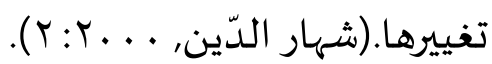

يمكن تحديد هذه الغاية في إقدار التلاميذ على أن يكتبوا بسرعة معقولة خطّا

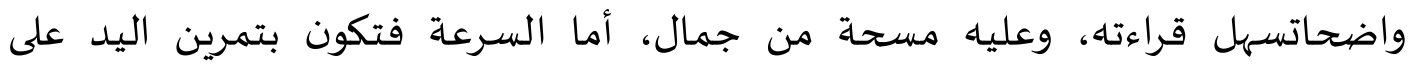

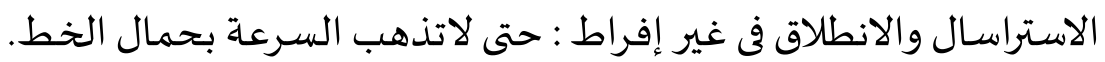

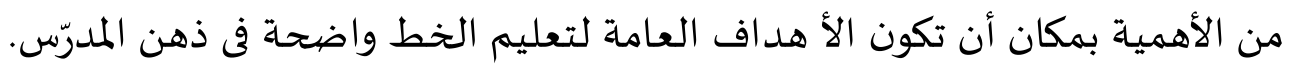
ليعمل على السير في الاتجاه الذي يؤدي - في النهاية - إلى تحقيقهاولعل أهمّتها هي (نايف

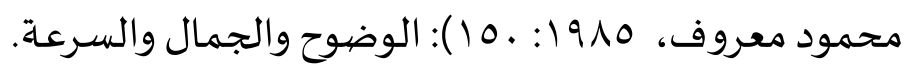

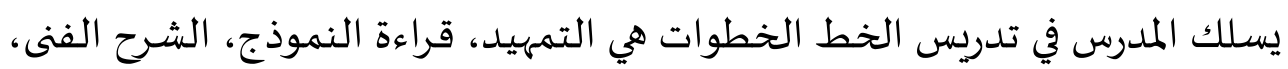

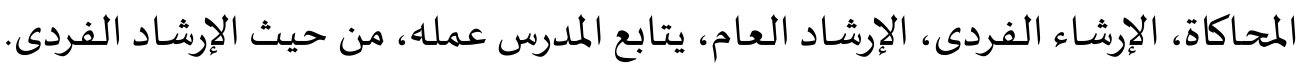


Ta'lim al-'Arabiyyah : Jurnal Pendidikan Bahasa Arab dan Kebahasaaraban, 2 (2), 2018

كما هو المكتوب في أغراض البحث أن الكاتبة تريد أن تعرف كيف أثر استخدام

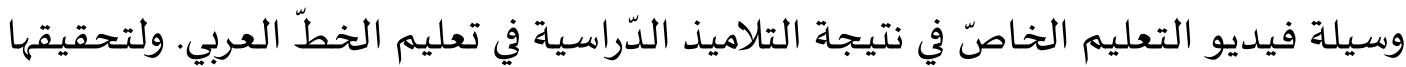

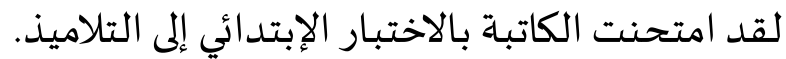

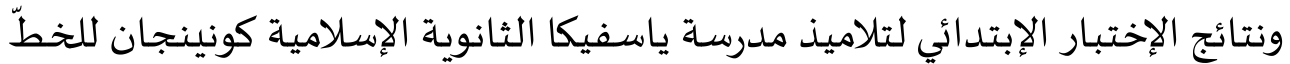

$$
\text { الجربد العي الدّرس الإضـافي كما في الجدول الآلتي: }
$$

\begin{tabular}{|c|c|c|c|c|c|}
\hline الجمل في & الاتساق في & 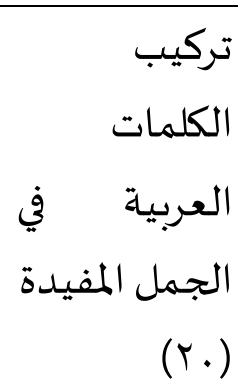 & 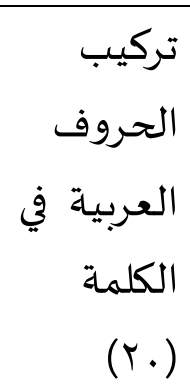 & كتابة & النمرة \\
\hline 19 & IV & سו & $1 \varepsilon$ & 1. & 1 \\
\hline IT & $1 \varepsilon$ & IT & 10 & 7 & r \\
\hline IT & 17 & IT & Ir & $r$ & r \\
\hline$r 7$ & 11 & IV & 19 & 1. & $\varepsilon$ \\
\hline IT & & IT & IT & $r$ & 0 \\
\hline & 17 & IT & $\Lambda$ & $r$ & 7 \\
\hline 10 & IV & 10 & 19 & $\Lambda$ & V \\
\hline$r$. & 10 & r & 17 & $V$ & $\Lambda$ \\
\hline r & 11 & 10 & 17 & 1. & 9 \\
\hline r & 10 & $\|$ & $\Lambda$ & 0 & 1. \\
\hline$r$. & 11 & IV & 17 & V & 11 \\
\hline IT & 10 & IT & $\wedge$ & $r$ & IT \\
\hline YI & 10 & r & 17 & 7 & $1 T$ \\
\hline 19 & 10 & سו & 17 & V & $1 \varepsilon$ \\
\hline 17 & 10 & r & $1 \varepsilon$ & 0 & 10 \\
\hline
\end{tabular}

المؤشـرات للمتغير السين الأول (س الاول) 
Ta'lim al-'Arabiyyah : Jurnal Pendidikan Bahasa Arab dan Kebahasaaraban, 2 (2), 2018

\begin{tabular}{|c|c|c|c|c|c|}
\hline Y) & 11 & 17 & 17 & 9 & 17 \\
\hline$T \varepsilon$ & 11 & 17 & 19 & 1. & IV \\
\hline ir & r & 11 & r & $\varepsilon$ & 11 \\
\hline r & 11 & IV & $r$. & 9 & 19 \\
\hline ir & Ir & $\wedge$ & $\wedge$ & 0 & $r$. \\
\hline 17 & 1. & $1 \varepsilon$ & $1 \varepsilon$ & $v$ & TI \\
\hline ir & 10 & ir & 17 & $\Lambda$ & rT \\
\hline 11 & IT & $\wedge$ & $\wedge$ & $\varepsilon$ & سr \\
\hline$r \varepsilon$ & 11 & IV & IV & 1. & TE \\
\hline 11 & 10 & $1 \varepsilon$ & $1 \varepsilon$ & $v$ & ro \\
\hline$\varepsilon Y Y$ & rAv & סrr & roo & $17 r$ & المجموع \\
\hline $17 ، \wedge \wedge \%$ & $10 . \varepsilon \wedge \%$ & $\|, \varepsilon \%$ & I乏.૫\% & $7 . \varepsilon \wedge \%$ & نجاح التدريس \\
\hline r.r人\% & r.।.\% & r.7人 \% & r.人乏\% & I.r.\% & نجاح المؤشرات \\
\hline
\end{tabular}

من الجدول السابق، يعرف بأن هناك التغير العلي لكل السؤال هو \% ـ ــ، من

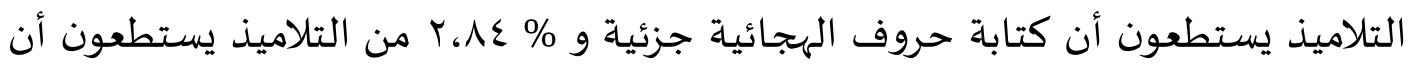

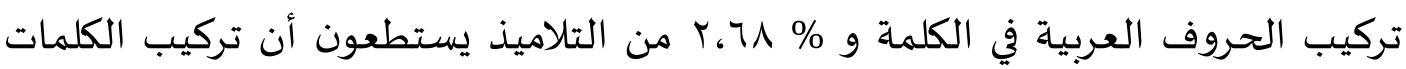

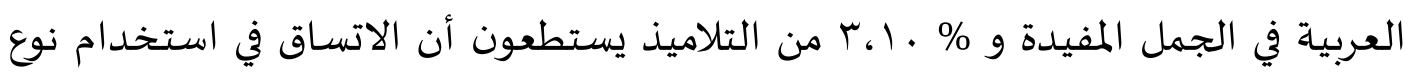

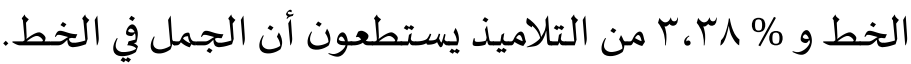
الجدول الثاني

\begin{tabular}{|r|r|}
\hline النتائج| & النمرة \\
\hline$V 1$ & $1 \varepsilon$ \\
\hline$V \varepsilon$ & 10 \\
\hline 9. & 17 \\
\hline 01 & $1 V$ \\
\hline$\varepsilon r$ & 11 \\
\hline
\end{tabular}

\begin{tabular}{|c|c|}
\hline النتائج & النمرة \\
\hline Vr & 1 \\
\hline 00 & $r$ \\
\hline VA & r \\
\hline 9. & $\varepsilon$ \\
\hline 17 & 0 \\
\hline
\end{tabular}


Ta'lim al- 'Arabiyyah : Jurnal Pendidikan Bahasa Arab dan Kebahasaaraban, 2 (2), 2018

\begin{tabular}{|c|c|c|c|}
\hline$\varepsilon 7$ & 19 & Tr & 7 \\
\hline 71 & $r$. & $0 \varepsilon$ & V \\
\hline NT & TI & V. & $\wedge$ \\
\hline$\Lambda$. & rr & $7 \pi$ & 9 \\
\hline$\wedge \mathrm{V}$ & r & or & 1. \\
\hline 09 & $r \varepsilon$ & $\varepsilon q$ & 11 \\
\hline \multirow[t]{2}{*}{71} & ro & VI & IT \\
\hline & & 01 & $\pi$ \\
\hline 1771 & \multicolumn{3}{|c|}{ مجموع } \\
\hline $7 \neg, r \varepsilon$ & & & متو \\
\hline
\end{tabular}

من الجدول السابق تعرف أن أعلى الدرجة من الاختبار الإبتدائي فهي على •9 وأدنى

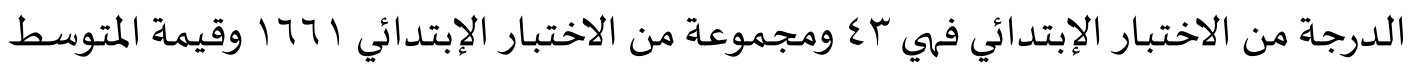
ع

وبعد قامت الكاتبة بالاختيار البعدي إلى تلاميذ للخطّ العربي في الدّرس الإضافي ،

$$
\text { فحصلت على النتائج كما في الجدول الآتي : }
$$

الجدول الثالث

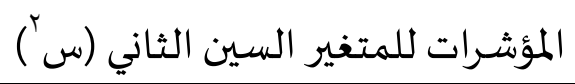

\begin{tabular}{|c|c|c|c|c|c|}
\hline الجمل في & الاتسـاق في & 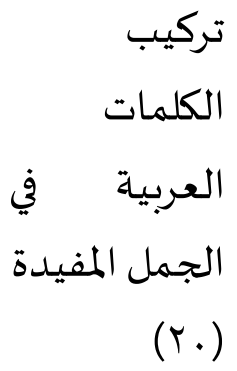 & 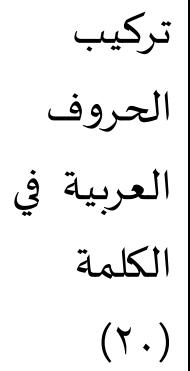 & كروف & النمرة \\
\hline$T \varepsilon$ & 19 & 10 & IV & $\wedge$ & 1 \\
\hline IT & 10 & $1 \varepsilon$ & $1 \varepsilon$ & V & r \\
\hline Ir & $1 \varepsilon$ & Ir & 10 & 7 & r \\
\hline TV & 11 & $r$. & $r$. & 1. & $\varepsilon$ \\
\hline
\end{tabular}


Ta'lim al-'Arabiyyah : Jurnal Pendidikan Bahasa Arab dan Kebahasaaraban, 2 (2), 2018

\begin{tabular}{|c|c|c|c|c|c|}
\hline 10 & 1. & 1. & 1. & 0 & 0 \\
\hline$r$. & 17 & 11 & IV & 1. & 7 \\
\hline 17 & IV & 10 & 19 & $\Lambda$ & V \\
\hline TV & IV & 11 & IV & $\Lambda$ & $\Lambda$ \\
\hline r. & 19 & 11 & 11 & 1. & $q$ \\
\hline 10 & 14 & $1 T$ & 10 & 7 & 1. \\
\hline$r$. & 11 & 17 & 19 & 1. & 11 \\
\hline 10 & r & 14 & $\Lambda$ & 0 & IT \\
\hline سץ & 11 & 11 & 17 & $\Lambda$ & M \\
\hline ro & 11 & 17 & 11 & 1. & $1 \varepsilon$ \\
\hline سץ & IV & 17 & 17 & V & 10 \\
\hline r. & 19 & r. & 11 & 1. & 17 \\
\hline YI & 11 & $1 \varepsilon$ & 11 & 1. & IV \\
\hline ro & IV & $1 \varepsilon$ & 17 & $\Lambda$ & 11 \\
\hline ru & r. & r. & r. & 1. & 19 \\
\hline 10 & 10 & 0 & 1. & 0 & $r$. \\
\hline 11 & 11 & r & $1 \varepsilon$ & V & rI \\
\hline 11 & 10 & 10 & 17 & $\Lambda$ & Tr \\
\hline 11 & 17 & 1. & $1 \varepsilon$ & 7 & r \\
\hline$r q$ & 19 & 19 & 11 & 1. & $r \varepsilon$ \\
\hline YI & 11 & 10 & $1 \varepsilon$ & $\Lambda$ & ro \\
\hline 019 & $\{17$ & rul & rqv & r.. & المجموع \\
\hline$r$. . V & $17.7 \varepsilon \%$ & I乏.VY\% & 10 ، А & $\wedge \%$ & نجاح التدرس \\
\hline$\varepsilon .10 \%$ & \% سז. & $r .9 \varepsilon \%$ & ץ. 11\% \% & $1.7 \%$ & نجاح المؤشرات \\
\hline
\end{tabular}


من الجدول السـابق، يعرف بأن هناك التغير العلي لكل السؤال هو \% 7، أ من التلاميذ

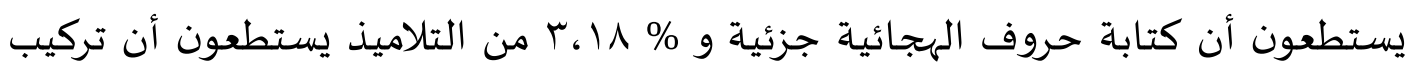

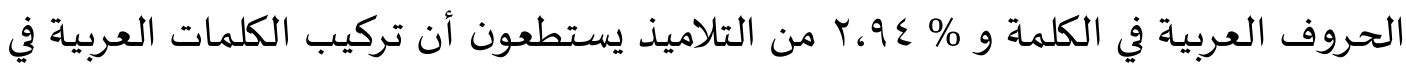

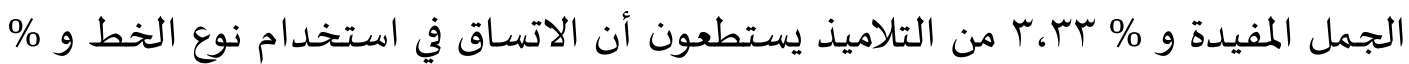

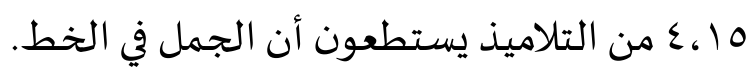

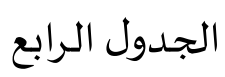

\begin{tabular}{|c|c|c|c|}
\hline النتائج & النمرة & النتائج & النمرة \\
\hline$\Lambda$. & $1 \varepsilon$ & 0. & 1 \\
\hline 11 & 10 & 0 . & r \\
\hline N & 17 & or & r \\
\hline N & IV & 7. & $\varepsilon$ \\
\hline N & 11 & 7. & 0 \\
\hline$\Lambda V$ & 19 & $7 T$ & 7 \\
\hline$\Lambda V$ & r. & $7 \varepsilon$ & V \\
\hline 90 & rI & 70 & $\Lambda$ \\
\hline 90 & Tr & $v$. & 9 \\
\hline 90 & r & $V \varepsilon$ & 1. \\
\hline 97 & $r \varepsilon$ & Vo & 11 \\
\hline \multirow[t]{2}{*}{$9 \mathrm{~V}$} & ro & VI & IT \\
\hline & & $v q$ & س \\
\hline $19 \ldots$ & \multicolumn{3}{|r|}{ مجموع } \\
\hline Vo, 9 & \multicolumn{3}{|r|}{ متوسط } \\
\hline
\end{tabular}

من الجدول السـابق تعرف أن أعلى النتيجة من الاختبار البعدي هي Vو وأدنى النتيجة

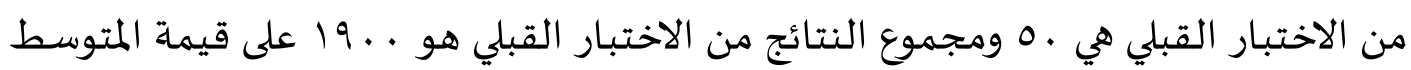

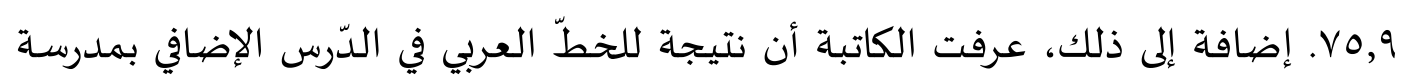


Ta'lim al-'Arabiyyah : Jurnal Pendidikan Bahasa Arab dan Kebahasaaraban, 2 (2), 2018

ياسفيكا الثانوية الإسلامية كونينجان على تكوين الخط العربي بعد استخدام وسيلة فيديو

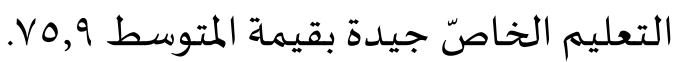
من الحساب السابق وجدت الكاتبة البيانات تدل على توزيع معتدل. وبذلك امتحان

$$
\text { "ت" بالخطوات الآتياة: }
$$

\begin{tabular}{|c|c|c|c|c|}
\hline \multirow[t]{2}{*}{ بي ' } & \multirow[t]{2}{*}{ بي } & \multicolumn{2}{|c|}{ 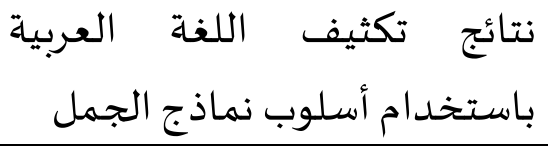 } & \multirow[t]{2}{*}{ ن } \\
\hline & & بعد & قبل & \\
\hline$\varepsilon q$ & V & 0 . & $\varepsilon r$ & 1 \\
\hline 17 & $\varepsilon$ & 0 . & $\varepsilon 7$ & r \\
\hline 17 & $\varepsilon$ & or & $\varepsilon q$ & r \\
\hline$\wedge 1$ & 9 & 7. & 01 & $\varepsilon$ \\
\hline 11 & 9 & 7. & 01 & 0 \\
\hline 11 & 9 & $7 r$ & or & 7 \\
\hline $1 \ldots$ & 1. & $7 \varepsilon$ & $0 \varepsilon$ & V \\
\hline $1 \ldots$ & 1. & 70 & 00 & $\Lambda$ \\
\hline$|r|$ & 11 & V. & 09 & 9 \\
\hline 179 & $1 \pi$ & $V \varepsilon$ & 71 & 1. \\
\hline 197 & $1 \varepsilon$ & vo & 71 & 11 \\
\hline 179 & Tr & VI & Tr & IT \\
\hline roT & 17 & Vq & Tr & $1 \pi$ \\
\hline $1 \ldots$ & 1. & $\Lambda$. & V. & $1 \varepsilon$ \\
\hline $1 \ldots$ & 1. & 11 & VI & 10 \\
\hline $1 \varepsilon \varepsilon$ & $1 T$ & $\Lambda r$ & VI & 17 \\
\hline $1 \ldots$ & 1. & $\Lambda r$ & $V r$ & IV \\
\hline 11 & 9 & $\Lambda r$ & $V \varepsilon$ & 11 \\
\hline
\end{tabular}

النتائج من الاختبار الإبتدائي والاختبار النهائي 
Ta'lim al-'Arabiyyah : Jurnal Pendidikan Bahasa Arab dan Kebahasaaraban, 2 (2), 2018

\begin{tabular}{|c|c|c|c|c|}
\hline$\wedge 1$ & 9 & $\Lambda \mathrm{V}$ & Vᄉ & 19 \\
\hline$\varepsilon q$ & V & $\Lambda V$ & $\Lambda$ & r. \\
\hline 179 & M & 90 & $\Lambda r$ & YI \\
\hline 11 & 9 & 90 & $\Lambda 7$ & rT \\
\hline $7 \varepsilon$ & $\Lambda$ & 90 & $\Lambda \mathrm{V}$ & אץ \\
\hline ry & 7 & 97 & 9. & $r \varepsilon$ \\
\hline$\varepsilon q$ & V & $9 V$ & 9. & ro \\
\hline$r \varepsilon \wedge q$ & rmq & المحموع & & \\
\hline
\end{tabular}

ومن البيان السابق الوجدت الكاتبة أن قيمة "ت" الحسابية على قدر VI, I 1 ، وقيماة

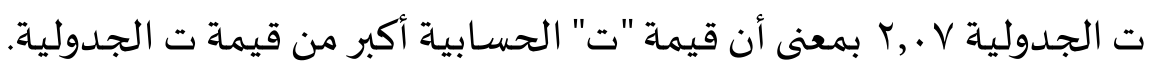

وبعد قامت الكاتبة بالاختبار البعدي إلى تلاميذ للخطّ العربي في الدّرس الإضـافي،

فحصلت على النتائج كما في الجـدول الآتي:

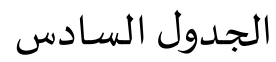

قيمة "د"

\begin{tabular}{|c|c|c|c|}
\hline قيمة "د" & نتيججة الاختبـار النهائي & نتيـجة الاختبـار الإبتـدائي & النمرة \\
\hline . ، $\leqslant r$ & N & VT & 1 \\
\hline . . 1 & $7 r$ & 09 & r \\
\hline $.01 T$ & 7. & 00 & r \\
\hline .01 & 90 & 9. & $\varepsilon$ \\
\hline$-\ldots r$ & 0 . & 01 & 0 \\
\hline .0 . & $V \varepsilon$ & 01 & 7 \\
\hline . . & Vo & $V \varepsilon$ & V \\
\hline . . & $\Lambda V$ & VI & $\Lambda$ \\
\hline . ^^V & 90 & $\Lambda r$ & $q$ \\
\hline $.01 \varepsilon$ & 7. & $0 \leqslant$ & 1. \\
\hline דו. . & & Vᄉ & 11 \\
\hline
\end{tabular}


Ta'lim al-'Arabiyyah : Jurnal Pendidikan Bahasa Arab dan Kebahasaaraban, 2 (2), 2018

\begin{tabular}{|c|c|c|c|}
\hline . . 1 & or & $\varepsilon q$ & IT \\
\hline - $6 \ 7$ & NH & VI & Ir \\
\hline תד. . & $\Lambda V$ & $V$. & $1 \varepsilon$ \\
\hline . $\measuredangle \Sigma V$ & 19 & r & 10 \\
\hline $1 \ldots$ & $9 V$ & $\Lambda$. & 17 \\
\hline-.67 & 11 & NV & IV \\
\hline .671 & $\Lambda$. & ror & 11 \\
\hline - “人 & 97 & 9 . & 19 \\
\hline$\cdots 1$ & 0. & $\varepsilon 7$ & $r$. \\
\hline . . To & V. & 71 & ri \\
\hline$\ldots 7$ & 70 & "ז & rt \\
\hline . & $7 \varepsilon$ & $\varepsilon$ & سז \\
\hline . “А & 90 & 17 & $r \varepsilon$ \\
\hline . ، $\leqslant r$ & V & 71 & ro \\
\hline . . & VI & $77 . \leq \varepsilon$ & مجمـوعـة \\
\hline$\ldots 1$ & & & متوسط \\
\hline متوسطة & جيد جـدا & جيد & تفسير \\
\hline
\end{tabular}

من الجدول السـابق، يعرف أن أعلى الدرجـة من قيمة "د" . . ، أ وأدنى الدرجة من قيمـة "د" . 7, . - وقيمة المتوسط ا .,. .. فوجدت الكاتبة قيمة التأثير لنتائج التلاميذ الدّراسية في تعليم الخطّ العربي بين ما قبل استخدام وسيلة فيديو التعليم الخاصّ وما بعده على قدر

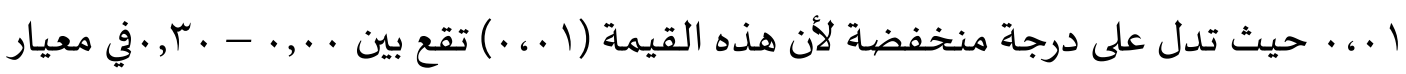
التفسير. 
النتائج التي تقدمتها الكاتبة في هذا البحث هي أن نتيجة التلاميذ في تعليم الخط العربي قبل استخدام وسيلة فيديو التعليم الخاصّ في خصـة الدّرس الإضـافي على أسـاس المؤشرات: كتابة الحروف الهجائية \% . ؟،ا وتركيب الحروف العربية في الكلمة \% عـ، ب وتركيب

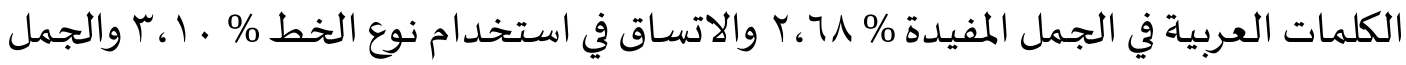

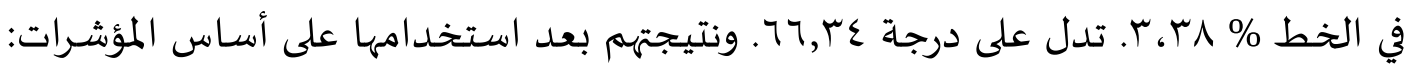

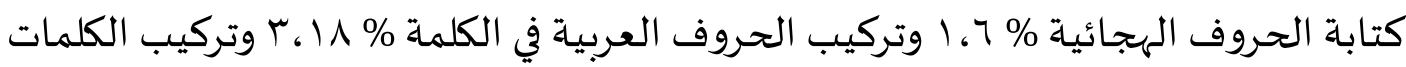

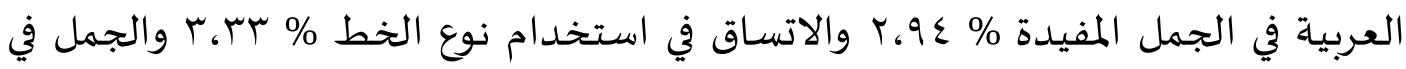

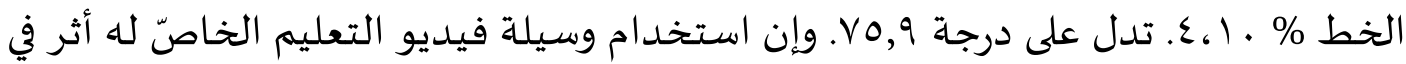
ترقية النتيجة الدراسية للخط العربي في الدّرس الإضافي، هناك فرق القيمة بينهما وتدل عليه

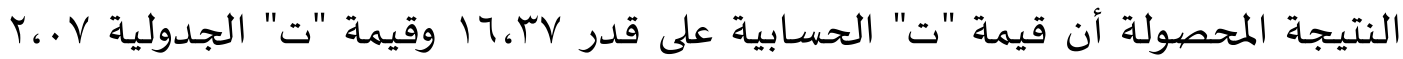
بمعنى أن قيمة "ت" الحسابية أكبر من قيمة "ت" الجدولية. وأما ترقية النتيجة فتدل عليه التهاهيه

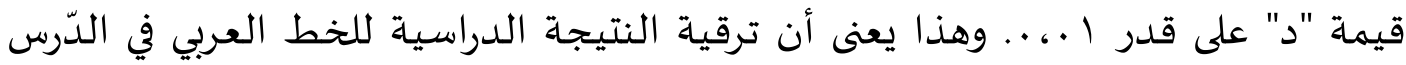
الإضافي من أثر استخدام وسيلة فيديو التعليم الخاصّ تدل على درجة منخفضهة في معيار التفسير.

\section{المراجع}

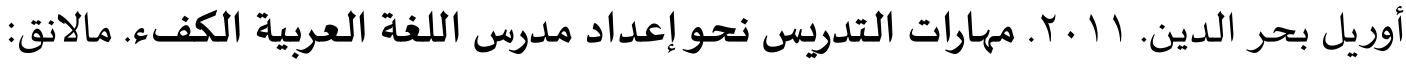
مطبعة جامعة مولانا مالك إبراهيم الإسلامية الحكومية مبالانق.

عبد الرحمن بن إبراهيم الفوزان. II ــ. إضاءات لمعلمى اللغة العربية لغير الناطقين بها. المملكة العربية السعودية.

عبد العليم إبراهيم. با97 اـ الموجه الفني لمدرسي اللغة العربية. مصر: دار المعارف. محمد علي الخولي. ب 191. أساليب تدريس اللغة العربية. المملكة العربية السعودية. نايف معروف.1910 ا خصيائص العربية وطرائق تدريسها. بيروت: دار النفائس. 
Ta'lim al-'Arabiyyah : Jurnal Pendidikan Bahasa Arab dan Kebahasaaraban, 2 (2), 2018

Arikunto, Suharsimi. 2013. Prosedur Penelitian Suatu Pendekatan Praktik. Jakarta: Rineka Cipta. Hamzah B Uno, Satria Koni. 2013. Assessment Pembelajaran. Jakarta: Bumi Aksara.

Hermawan, Acep.201l. Metodologi Pembelajaran Bahasa Arab. Bandung: Remaja Rosdakarya.

Izzan, Ahmad. 201l. Metodologi Pembelajaran Bahasa Arab. Bandung: Humaniora.

Mahmud. 201l. Metode Penelitian Pendidikan. Bandung: Pustaka Setia.

Rahayu, Yayu Nurhayati. 2015. Statistka Pendidikan Teori Dan Aplikasi. Bandung (tidak diterbitkan).

Rusman.2014. Model-modelPembelajaran. Jakarta: Pustaka Panjimas.

Slameto. 2010. Belajar dan Faktor-faktoryang Mempengaruhinya. Jakarta: Rineka Cipta.

Syah, Muhibbin. 2013. Psikologi Pendidikan. Bandung: PT Remaja Rosdakarya.

Syaharuddin. 2000. Teknik Pengolahan Kaligrafi Dekorasi. Jakarta: Kalimah.

Syaiful Bahri Djamarah, Azwan Zain. 2013. Strategi Belajar Mengajar. Jakarta: Bumi Aksara. 